\title{
Effect of an Interventional Health Education Program on the Practice of Caregivers towards Infection Control Measures in Mygoma Orphanage Center 2014-2017
}

\author{
Fathia H. Ismail ${ }^{1 *}$, Mohamed Osman ${ }^{2}$, Eisa O. El-Amin ${ }^{3}$ \\ ${ }^{1}$ Department of Nursing ,College of Medical Applied Sciences, Buraydah Private Colleges, Qassim, Kingdom of Saudi Arabia, The National Ribat \\ University, Khartoum, Sudan \\ ${ }^{2}$ Modern Medical Center, Khartoum, Sudan \\ ${ }^{3}$ Faculty of Medicine, the National Ribat University, Khartoum, Sudan
}

DOI: $\underline{10.36348 / \text { sjnhc.2020.v03i12.006 }}$

| Received: 11.12.2020 | Accepted: 21.12.2020 | Published: 26.12.2020

*Corresponding author: Dr. Fathia Hassan Ismail

\section{Abstract}

Background: Infection is a major health problem in orphanage centers and represents a major cause of morbidity and mortality among residents. Health education is an essential component of infection control and should be offered to all children and their caregivers. The aim of current study: to evaluate the effect of a health education program about infection control on practice of caregivers \& on infection rates in Mygoma orphanage center. Materials and methods: An Intervention study (Quasi-experimental: pre and posttest design for the same group). The study was conducted in Mygoma orphanage center in Khartoum state. The study sample consisted of 92 caregivers. Data were collected using a checklist to measure practice and laboratory investigations. The intervention program included infection control lectures, handouts, posters, and attention to environmental cleaning and disinfection. Compliance with these measures was monitored and recorded. Data were analyzed using Statistical Packages for Social Sciences (SPSS). Results: the study showed significant differences were found regarding correct practices between the pretest and posttest $(\mathrm{P}<0.05)$ also the study revealed that, the swab for culture and sensitivity, in food table the isolated organisms were staph $23.1 \%$, E coli 7.7\%, Protus 7.7\%, Bacillus 7.7\%. and klebseilla 15.4\% at pretest investigation, while at posttest the isolated organisms were staph $15.4 \%$, and klebseilla $7.7 \%$. In diapering table, the isolated organisms were staph $15.4 \%$, E coli $30.7 \%$, Protus $7.7 \%$, klebseilla $15.4 \%$ and Pseudomonas $7.7 \%$ at pretest investigation, while at posttest measurement the isolated organisms were E coli $15.4 \%$ and klebseilla $7.7 \%$. Conclusion: The study concluded that educational and environmental infection control program had a significant impact related to the improvement of the caregiver's practice skills and decrease in infection rates post application of the program.

Key words: Health education program, practice, Caregivers, infection control measures, Mygoma orphanage.

Copyright (C) 2020 The Author(s): This is an open-access article distributed under the terms of the Creative Commons Attribution 4.0 International License (CC BY-NC 4.0) which permits unrestricted use, distribution, and reproduction in any medium for non-commercial use provided the original author and source are credited.

\section{INTRODUCTION}

Infection control program was a protocol in every hospital to stop the spurt of communicable diseases in various health settings. Apparently, programs have been started and extended in other institutions like schools and childcare centers, where they focused in controlling the infection among the specific population [1]. Furthermore, the program was also recognized in the community and group homes, where the infection control strategies is very much needed such as overcrowding, food preparation, sewage disposal and other possible health concerns [2]. The Worldwide Orphans Foundation (WWO) and the Wide Horizons for Children (WHFC) introduced a manual for orphans in 2009, containing recommendations in details for inhibiting infection among orphan institutions which includes Hand hygiene, Bathing practices, Diaper changing, Clothing and sleeping equipment, General cleanliness and Other concerns regarding caregivers and staff [3].In addition such precautions and guidelines were formulated to help staff and caregivers in providing the necessary attention, care and techniques to totally prevent infection in specific health care setting[4].

\section{MATERIALS AND METHODS}

The materials and methods begins by presenting the research design, followed by setting and duration of the study, sample, sample size, data collection technique and tools, phases of the study, 
validity and reliability of instruments and ethical consideration.

\section{Study design}

A Quasi-experimental study: pretest and posttest for the same group.

\section{Study setting}

Sudan

Mygoma Orphanage center, Khartoum state,

\section{Sample}

Care givers deal with abandoned children in Mygoma orphanage center during the study period.

\section{Sample size}

The recommended sample size given by the total coverage of caregivers (120), but there are 17 refused to be included and 11 were excluded because either they went for a vacation or resigned from their posts. So the total numbers of participants were 92 caregivers.

\section{DATA COLLECTION TECHNIQUE AND TOOLS}

Two tools were used to collect the needed data to achieve the aim of the study, they were: Infection control and hygienic checklist to assess the caregiver's performance regarding infection control in orphanage center and Bacteriological assessment that included swab for culture and sensitivity from all food tables and diapering tables in the children's rooms at the time of study before and after the intervention program.

\section{DATA ANALYSIS}

The collected data as pretest and posttest organized, categorized, tabulated using mean and standard deviation. The statistical package for social sciences (SPSS version 20) was used for analysis.

\section{Phases of the study}

Pre intervention phase: Baseline survey was conducted.

Intervention phase: Started from (JuneSeptember, 2016), the education was given through lectures, small group work, demonstration and remonstration regarding infection prevention and control.

Post Intervention Monitoring: The researcher started a posttest after memory gap six months. She was using the same tools to compare between pre and post intervention program which were conducted to evaluate the effect of the program on respondents.

Ethical Consideration: An official letter was taken from the National Al Ribat University to Mygoma orphanage center administrator for permission to carry out the study. Participants provided verbal consent to participate they have also been assured of confidentiality and of freedom to withdraw without conditions.

\section{RESULTS}

Total numbers of respondents were 92 and 13 focusing on the different surfaces in the children's rooms. The results of the present study are shown in tables respectively: (Table 1) the mean value of the caregivers regarding satisfaction on the item 1 of child feeding practice at pretest measurement was $(1.00 \pm 0.00)$ and at posttest measurement was $(1.17 \pm 0.51)$. On the item 2 of this dimension at pretest measurement the mean value was $(1.00 \pm 0.00)$ and at posttest measurement was $(1.17 \pm 0.51)$. The mean value of the item 3 of this practice at pretest measurement was $(1.29 \pm 0.46)$ and at posttest measurement was $(2.29 \pm 0.83)$. The mean value of the caregivers regarding satisfaction on the item 4 of this practice at pretest measurement was $(1.54 \pm 0.50)$ and at posttest measurement was $(2.57 \pm 0.65)$. (Table 2) Bathing practices: the techniques and precautions needed to be looked into and was changed after the interventions were carried out indicates significance differences between pretest and posttest measurements in all items $(\mathrm{P}<0.05)$. (Table 3) Diapers care; The mean value of the caregivers regarding satisfaction on the item 2 of diaper care at pretest measurement was $(1.01 \pm 0.00)$ and at posttest measurement was $(1.95 \pm 0.86)$ indicates significance differences between pretest and posttest measurements in this item $(\mathrm{P}<0.05)$. The mean value of the caregivers regarding satisfaction on the item 3 at pretest measurement was $(1.00 \pm 0.00)$ and at posttest measurement was $(2.18 \pm 0.74)$ indicates significance differences between pretest and posttest measurements in this item $(\mathrm{P}<0.05)$. The mean value of the caregivers regarding satisfaction on the item 4 at pretest measurement was $(1.00 \pm 0.00)$ and at posttest measurement was $(2.12 \pm 0.89)$ indicates significance differences between pretest and posttest measurements in this item $(\mathrm{P}<0.05)$. The mean value of the item 5 at pretest measurement was $(1.07 \pm 0.25)$ and at posttest measurement was $(2.39 \pm 0.63)$ indicates significance differences between pretest and posttest measurements in this item $(\mathrm{P}<0.05)$. The mean value of the item 6 at pretest measurement was $(1.00 \pm 0.00)$ and at posttest measurement was $(2.83 \pm 0.57)$ indicates significance differences between pretest and posttest measurements in this item $(\mathrm{P}<0.05)$. (Table 4) Shows swabs for culture and sensitivity, in food table the isolated organisms were staph $23.1 \%$, E coli $7.7 \%$, Protus $7.7 \%$, Bacillus $7.7 \%$. and klebseilla $15.4 \%$ at pretest investigation, while at posttest the isolated organisms were staph $15.4 \%$, and klebseilla $7.7 \%$. In diapering table, the isolated organisms were staph $15.4 \%$, E coli $30.7 \%$, Protus $7.7 \%$, klebseilla $15.4 \%$ and Pseudomonas $7.7 \%$ at pretest investigation, while at posttest measurement the isolated organisms were $\mathrm{E}$ coli $15.4 \%$ and klebseilla $7.7 \%$. 
Table-1: Differences in the degree of satisfaction regarding caregivers, s feeding practice in Mygoma Orphanage center 2014-2017 at pre and posttest measurements $(n=184)$

\begin{tabular}{|l|l|l|l|l|l|l|l|l|l|l|l|}
\hline \multirow{2}{*}{ Items } & Pre & \multicolumn{2}{l}{ SE } & \multicolumn{2}{l|}{ C/I 95\% } & T & DF & \multirow{2}{*}{ P } \\
\cline { 2 - 9 } & Mean & SD & Mean & SD & & Lower & Upper & & & & \\
\hline & & & & & & & & & \\
\hline $\begin{array}{l}\text { 1. Do caregivers wash their hands } \\
\text { Before feeding each child? }\end{array}$ & 1.00 & 0.00 & 1.17 & 0.51 & 0.05 & -0.28 & -0.07 & -3.3 & 182 & 0.012 \\
\hline $\begin{array}{l}\text { 2.Do caregivers wash their } \\
\text { hands after feeding each child? }\end{array}$ & 1.00 & 0.00 & 1.17 & 0.51 & 0.05 & -0.28 & -0.07 & -3.3 & 182 & 0.012 \\
\hline $\begin{array}{l}\text { 3.Are surfaces used to serve } \\
\text { food cleaned and sanitized before } \\
\text { meal? }\end{array}$ & 1.29 & 0.46 & 2.29 & 0.83 & 0.10 & -1.20 & -0.80 & -10.1 & 182 & 0.002 \\
\hline $\begin{array}{l}\text { 4.Are surfaces used to serve } \\
\text { food cleaned and sanitized after } \\
\text { meal? }\end{array}$ & 1.54 & 0.50 & 2.57 & 0.65 & 0.09 & -1.19 & -0.85 & -11.9 & 182 & 0.001 \\
\hline
\end{tabular}

Table-2: Differences in the degree of satisfaction regarding caregivers, $s$ bathing practices in Mygoma Orphanage center 2014-2017 before and after program $(n=184)$

\begin{tabular}{|l|l|l|l|l|l|l|l|l|l|l|l|}
\hline \multirow{2}{*}{ Items } & Pre & \multicolumn{2}{l|}{ Post } & \multicolumn{2}{l|}{ C/I 95\% } & T & DF & P \\
\cline { 2 - 7 } & Mean & SD & Mean & SD & & Lower & Upper & & & \\
\hline $\begin{array}{l}\text { 1. Are shower areas, basins and } \\
\text { sinks used for bathing babies } \\
\text { and children are cleaned and } \\
\text { disinfected prior to use? }\end{array}$ & 1.00 & 0.00 & 1.40 & 0.79 & 0.08 & -0.56 & -0.24 & -4.91 & 182 & 0.013 \\
\hline $\begin{array}{l}\text { 2. Are shower areas, basins and } \\
\text { sinks used for bathing babies } \\
\text { and children are cleaned and } \\
\text { disinfected after use? }\end{array}$ & 1.00 & 0.00 & 2.22 & 0.87 & 0.09 & -1.40 & -1.04 & -13.35 & 182 & 0.001 \\
\hline $\begin{array}{l}\text { 3. Do caregivers wash their hands } \\
\text { prior to bathing children/babies? }\end{array}$ & 1.00 & 0.00 & 1.77 & 0.87 & 0.09 & -0.95 & -0.59 & -8.55 & 182 & 0.003 \\
\hline $\begin{array}{l}\text { 4. Do caregivers wash their hands } \\
\text { after bathing children/babies? }\end{array}$ & 1.00 & 0.00 & 2.28 & 0.77 & 0.08 & -1.44 & -1.12 & -15.87 & 182 & 0.001 \\
\hline
\end{tabular}

Table-3: Differences in the degree of satisfaction regarding diaper care in Mygoma Orphanage center 2014-2017

\begin{tabular}{|c|c|c|c|c|c|c|c|c|c|c|}
\hline \multirow[t]{2}{*}{ Items } & \multicolumn{2}{|l|}{ Pre } & \multicolumn{2}{|l|}{ Post } & \multirow[t]{2}{*}{ SE } & \multicolumn{2}{|c|}{ C/I 95\% } & \multirow[t]{2}{*}{$\mathbf{T}$} & \multirow[t]{2}{*}{ DF } & \multirow[t]{2}{*}{$\mathbf{P}$} \\
\hline & Mean & SD & Mean & SD & & Lower & Upper & & & \\
\hline $\begin{array}{l}\text { 1. Are diapers changing } \\
\text { surfaces made of impervious } \\
\text { material and free of } \\
\text { cracks or crevices? }\end{array}$ & 2.11 & 1.00 & 2.11 & 1.00 & 0.15 & -0.29 & 0.29 & 0.11 & 182 & 0.09 \\
\hline $\begin{array}{l}\text { 2.Do caregivers wash their } \\
\text { hands before changing diapers? }\end{array}$ & 1.01 & 0.10 & 1.95 & 0.86 & 0.05 & -0.83 & -0.65 & -16.06 & 182 & 0.001 \\
\hline $\begin{array}{l}\text { 3. Do caregivers wash children's } \\
\text { hands after changing diapers? }\end{array}$ & 1.00 & 0.00 & 2.18 & 0.74 & 0.03 & -2.02 & -1.90 & -13.99 & 182 & 0.001 \\
\hline $\begin{array}{l}\text { 4. Do caregivers clean and } \\
\text { sanitize the diaper changing } \\
\text { surfaces after each use? }\end{array}$ & 1.00 & 0.00 & 2.12 & 0.89 & 0.08 & -1.34 & -1.03 & -15.35 & 182 & 0.001 \\
\hline $\begin{array}{l}\text { 5. Do caregivers wash their } \\
\text { hands after changing diapers? }\end{array}$ & 1.07 & 0.25 & 2.39 & 0.63 & 0.09 & -1.30 & -0.94 & -11.06 & 182 & 0.001 \\
\hline $\begin{array}{l}\text { 6. Are there instructional signs } \\
\text { posted showing proper diaper } \\
\text { changing techniques? }\end{array}$ & 1.00 & 0.00 & 2.83 & 0.57 & 0.07 & -1.47 & -1.19 & -18.83 & 182 & 0.001 \\
\hline
\end{tabular}


Table-4: Swabs for culture and sensitivity from surfaces in the children's rooms before and after attendance of the program in Mygoma Orphanage center 2014-2017 $(n=26)$

\begin{tabular}{|l|l|l|l|l|l|}
\hline \multirow{2}{*}{} & \multicolumn{3}{l}{ Group } \\
\cline { 3 - 6 } & & Pre $(\mathrm{n}=13)$ & \multicolumn{2}{l|}{ Post (n=13) } \\
\cline { 3 - 6 } & N & $\%$ & $\mathrm{~N}$ & $\%$ \\
\hline \multirow{2}{*}{ Food table } & & & & \\
\hline \multirow{2}{*}{} & Staph & 5 & 38.5 & 10 & 76.9 \\
\hline & E.coli & 3 & 23.1 & 2 & 15.4 \\
\hline & Protus & 1 & 7.7 & 0 & 0.0 \\
\hline & Bacillus & 1 & 7.7 & 0 & 0.0 \\
\hline & Klebsiella & 2 & 15.4 & 1 & 7.7 \\
\hline Diapering table & No growth & 3 & 23.1 & 10 & 76.9 \\
\hline & Staph & 2 & 15.4 & 0 & 0.0 \\
\hline & E.coli & 4 & 30.7 & 2 & 15.4 \\
\hline & Protus & 1 & 7.7 & 0 & 0.0 \\
\hline & Klebsiella & 2 & 15.4 & 1 & 7.7 \\
\hline & Pseudomonas & 1 & 7.7 & 0 & 0.0 \\
\hline
\end{tabular}

\section{DISCUSSION}

It is generally agreed that implementation of infection control program in orphanage center is important in minimizing disease transmission [5]. Correct practices of the caregivers were significantly improved after application of the program.

Concerning child feeding practices, most caregivers did not wash their hands or washed it but not satisfactory before child feeding. All caregivers did not wash their hands after feeding each child. Most caregivers did not clean and sanitize tabletops before and after serving food. Results indicated that slight improvement occurred in child feeding practice by care givers after attendance of the program (table1). Our study was comparable to a study conducted on Boston which stated that a multifactorial intervention emphasizing alcohol-based hand sanitizer use in the home reduced transmission of GI illnesses within families with children in child care. Hand sanitizers and multifaceted educational messages may have a role in improving hand-hygiene practices within the home setting [6]. In the dimension of bathing children, the center does not have bathing facilities for infants and young children (a regular installed bathtub, infant-size bathtub or large sink within the washroom area and stack of clean towels available and wash them after each use). The children were bathed in sink that used for diapering and hand washing for staff. Also the center has no a clear plan for cleaning and disinfection to be followed by caregivers (Table 2). Regarding diaper care, the center was not provided with enough numbers of diapering tables. In some rooms surface of diapering tables were not free of cracks or crevices that are difficult to clean and sanitize after every use. There was no separate, dedicated hand washing sink for staff in the nappy change areas, no hand-washing facilities (liquid soap and single serve towels, wipes, and creams labeled and stored separately for each child, special waste containers with lids that operate by a foot pedal and diapering procedure poster to ensures the health and safety of staff, and the caregivers were not flow the hygienic practice during nappy changing process (Table 3 ). This was comparable to a previous study conducted in North Carolina about hand-washing and diapering equipment reduces disease among children in out-ofhome child care centers. The results show that hygiene and sanitation behaviors was improved in both intervention and control centers and also there was a significant difference favoring the intervention centers with respect to frequency of diarrheal illness $(0.90 \mathrm{vs}$ 1.58 illnesses per 100 child-days in control centers)[7].

Concerning bacteriological assessment about swabs for culture and sensitivity from surfaces in the children's rooms before and after attendance of the program results revealed that, in food tables the isolated organisms were staph $23.1 \%$, E coli $7.7 \%$, Protus $7.7 \%$, Bacillus $7.7 \%$. and klebseilla $15.4 \%$ at pretest investigation, while at posttest the isolated organisms were staph $15.4 \%$, and klebseilla $7.7 \%$. In diapering table, the isolated organisms were staph $15.4 \%$, E coli $30.7 \%$, Protus 7.7\%, klebseilla $15.4 \%$ and Pseudomonas $7.7 \%$ at pretest investigation, while at posttest measurement the isolated organisms were $\mathrm{E}$ coli $15.4 \%$ and klebseilla $7.7 \%$. (Table 4). Results indicate that improvement was occurred about swabs for culture and sensitivity from surfaces in the children's rooms after attendance of the program. Our study was comparable with a previous study of Cole et al. about comprehensive family hygiene promotion in peri-urban Cape Town: Gastrointestinal and respiratory illness and skin infection reduction in children aged fewer than 5 . The result show that there is meaningful reduction of gastrointestinal and respiratory illnesses and skin infections across all communities, families with hygiene education plus the consistent use of provided hygiene products experienced greater illness reduction in children aged under 5 years [8]. But disagreed with study of Zomer et al., they said that no 
evidence for an effect of the intervention was demonstrated on the incidence of episodes of diarrhea and the common cold [9].

\section{CONCLUSION}

According to the study findings the researcher concluded that: there was significant statistical improvement in the practical skills and infection rate after educational program. There was a better practice after attendance of the program had seen among the caregivers regarding infection control in terms of hand washing, cleaning and disinfection, diapering demonstration. $(\mathrm{P}<0.05)$ in all aspect indicates statistically significant difference. And infection rate after an interventional health education program in orphanage center found to be decreased.

\section{ACKNOWLEDGEMENTS}

We thank the administration and staff in Mygoma Orphanage Centre for their enthusiastic support and cooperation throughout this study.

\section{REFERENCES}

1. Drew. (2005). Infection Control Guidelines for Community Shelters and Group Homes. Manitoba Advisory Committee on Infectious Disease.

2. Peel Public Health (ON). (2011). Take Charge: A Guide to Infection Prevention and Control in Homeless Shelters [Internet]. Mississauga (ON): Peel Public Health.

3. Mengistu, S., Habtu, A. (2009). Worldwide Orphans Foundation and Wide Horizons for Children Orphan Care Manual. New Jersey: Worldwide Orphans Foundation.
4. Roberts, C., Gibson, Z., Hath way, N. (2014). Infection Prevention and Control for Childcare Settings (0-5 years) [Internet]. London (UK): Public Health Wales.

5. Krilov, L. R., Barone, S. R., Mandel, F. S., Cusack, T. M., Gaber, D. J., \& Rubino, J. R. (1996). Impact of an infection control program in a specialized preschool. American Journal of Infection Control, 24(3), 167-173.

6. Sandora, T. J., Taveras, E. M., Shih, M. C., Resnick, E. A., Lee, G. M., Ross-Degnan, D., \& Goldmann, D. A. (2005). A randomized, controlled trial of a multifaceted intervention including alcohol-based hand sanitizer and hand-hygiene education to reduce illness transmission in the home. Pediatrics, 116(3), 587-594.

7. Kotch, J. B., Isbell, P., Weber, D. J., Nguyen, V., Savage, E., Gunn, E., \& Allen, J. (2007). Handwashing and diapering equipment reduces disease among children in out-of-home child care centers. Pediatrics, 120(1), e29-e36.

8. Cole, E. C., Hawkley, M., Rubino, J. R., Crookston, B. T., McCue, K., Dixon, J., \& Kim, J. (2012). Comprehensive family hygiene promotion in peri-urban Cape Town: Gastrointestinal and respiratory illness and skin infection reduction in children aged fewer than 5. South African Journal of Child Health, 6(4), 109-117.

9. Zomer, T. P., Erasmus, V., Looman, C. W., TjonA-Tsien, A., Van Beeck, E. F., De Graaf, J. M., ... \& Voeten, H. A. C. M. (2015). A hand hygiene intervention to reduce infections in child daycare: a randomized controlled trial. Epidemiology \& Infection, 143(12), 2494-2502. 